\title{
Evaluation of stress responses induced by the loading density in dromedary camel (Camelus dromedarius)
}

\author{
Abdelilah Lemrhamed', Mohamed Farh'1, Fouad Riad', Najia El Abbadi², Elhassane Tahri', \\ Abderrahmane Belhouari', Bernard Faye ${ }^{3}$, Mohammed El Khasmi ${ }^{*}$
}

\begin{abstract}
${ }^{1}$ Laboratory of Physiopathology and Molecular Genetics, Ben M'Sik Faculty of Sciences, Hassan II University of Casablanca, BP 7955 Sidi Othmane, Casablanca, Morocco, ${ }^{2}$ Unit of Radio-Immuno-Analysis/Division of Life Sciences, CNESTEN, BP 1382 RP 10001, Rabat, Morocco, ${ }^{3} F A O / C I R A D-E S$, Campus International de Baillarguet, TA C/dir B 34398 Montpellier, France
\end{abstract}

\section{A B S TR A C T}

\begin{abstract}
The intensity of stress depends on several external factors, such as distance and conditions of transport, climate change, the nature of the journey and the vehicle used, etc. Our research aims to study the effect of loading density on certain physiological, hematological, biochemical and hormonal parameters in camels. Sixteen male animals belonging to the municipal slaughterhouse of Casablanca (west of Morocco) were divided into two groups of 8 camels to study the effect of 2 loading densities: $1 \mathrm{camel} / 2-3.6 \mathrm{~m}^{2}$ (Group I) and $1 \mathrm{camel}^{2} 1.44-1.80 \mathrm{~m}^{2}$ (Group II). Hct, NLR, H\% and biochemical parameters were analyzed in our laboratory (LPGM) at the Ben M'Sik Faculty of Sciences in Casablanca, while the hormones were analyzed by radioimmunology at the National Center of Energy, Sciences and Nuclear Techniques of Maâmoura, Morocco. In Groups I and II, rectal temperature, heart and respiratory rates, hemolysis, neutrophil/lymphocyte ratio and plasma levels of Glu, COR, $T_{3}$ and $T_{4}$ showed a significant increase $(P<0.05)$ at the end of transport just after unloading by comparison to those measured before loading and transport. All these parameters were significantly $(\mathrm{P}<0.05)$ higher in Group II than those observed in Group I. An increase of the loading density $\left(1 \mathrm{camel} / 1.44-1.80 \mathrm{~m}^{2}\right)$ during road transport is considered as a stressful factor that could alter the physiology of the dromedary and influence the postmortem quality of its meat. The impact of this factor on the antioxidant status of this species will be studied later.
\end{abstract}

Keywords: Dromedary; Hormones; Leukocyte formula; Loading density; Preslaughter stress

\section{INTRODUCTION}

Because of its expected dietetic quality, camel meat could have an advantage for human consumers (Kadim et al., 2013). But, the steps preceding the slaughter of an animal for human consumption need a rigourous control to maintain product quality as well as for protecting animal welfare (Shimshony and Chaudry, 2005). During the preslaughter phases, domestic animals are exposed to stressinducing factors (Terlouw et al., 2005; Deiss et al., 2009). Such stressful situation was evaluated by behavioural and physiological reactions in cows (Bourguet et al., 2010), lambs (Deiss et al., 2009), pigs (Terlouw et al., 2005) and camels (El Khasmi et al., 2013; 2015). There is good scientific evidence that many factors related to preslaughter stress can affect the well-being and meat quality of animals, and contribute indirectly to increasing the risks to food safety (Nielsen et al., 2011). Among these factors handling, loading, movement, immobilization, transport, unloading and waiting should be considered, because it compromises the welfare of animals and increases their vulnerability to disease (Rostagno, 2009; Broom, 2014).

Stress effects can be evaluated by using physiological, hematological, biochemical and hormonal approaches. Thus, enzymes, hormones, glycolytic potential, proteins, oxidative stress, lipid peroxidation and tissue damage were estimated to assess stress responses (Grandin, 2013).

On the other hand, slaughter methods, if not optimally employed, can adversely affect quality, operator and food safety and as a result cause downgrading of carcass and meat (Shimshony and Chaudry, 2005). Several works had reported that stocking density influenced the welfare of animals (Dalla Costa et al., 2007; De la Fuente et al., 2010), but scarce informations are available regarding this in the

\footnotetext{
*Corresponding author:

Mohammed El Khasmi, Laboratory of Physiopathology and Molecular Genetics, Ben M'Sik Faculty of Sciences, Hassan II University of Casablanca, BP 7955 Sidi Othmane, Casablanca, Morocco. E-mail: elkhasmimohammed@gmail.com
}

Received: 28 April 2018; $\quad$ Accepted: 25 August 2018 
camel. The present study evaluates the preslaughter stress induced by loading density by analyzing rectal temperature (RT), heart rate (HR), respiratory rate (RR), hematocrit (Hct), neutrophile to lymphocyte ratio (NLR), hemolysis, and circulating levels of glucose (Glu), total protein (TP), cholesterol (CT), urea, creatinine, aminotransferase (ALAT), aspartate aminotransferase (ASAT), calcium (Ca), phosphorus $(\mathrm{Pi})$, magnesium $(\mathrm{Mg})$, cortisol (COR), total triiodothyronine $\left(\mathrm{T}_{3}\right)$ and total thyroxine $\left(\mathrm{T}_{4}\right)$ in the dromedary camel. These physiological, heamatological, biochemical and hormonal parameters are considered as indicators of stress responses in the camel (El khasmi et al., 2010; 2013; 2015).

\section{MATERIALS AND METHODS}

\section{Animals}

The study was carried out at Casablanca Municipality slaughterhouse in the West of Morocco (North of Africa, latitude $33^{\circ} 34^{\prime} 42.44^{\prime \prime} \mathrm{N}$, longitude $7^{\circ} 36^{\prime} 23.89^{\prime \prime}$ O) using 16 adult one-humped male camels (Camelus dromedarius), aged 4-7 years. These animals were living under similar conditions, fed with some barley concentrate and dry hay straw and exposed to the same preslaughter conditions. After arrival in the slaughterhouse, they were placed in the waiting station and were slaughtered following routine commercial slaughterhouse procedures according to Halal method. These camels were divided into 2 groups of 8 camels to study the effect of low and high loading densities: respectively $1 \mathrm{camel} / 2-3.6 \mathrm{~m}^{2}$ (Group I) and $1 \mathrm{camel} / 1.44-1.80 \mathrm{~m}^{2}$ (Group II). The densities were related to the space available within the truck and were determined as total number of animals divided by area of truck.

\section{Road transport}

All camels were transported by truck for 72 to $80 \mathrm{~km}$ at an average $60-65 \mathrm{~km} / \mathrm{h}$ speed. All camels were clinically healthy and feed deprived overnight. They were transported in a side-facing position and squatting position holding the forelegs tight by a rope at the knees. During transportation, the camels could not feed and drink, and the road was asphalted until the arrival to the slaughterhouse. They were carefully unloaded on arrival at the abattoir to avoid stress and were calmly guided into the waiting station.

\section{Physiological parameters measure}

Physiological parameters (RT, HR and RR) were measured just before the loading and at the end of transport just before the unloading of camels. RT was measured by an ordinary thermometer introduced the rectum of the animal. HR (beats/min) was determined by auscultation of the heart area. Wheras, RR (breaths/min) was determined by auscultation of the trachea.

\section{Blood sampling}

Just before the loading and at the arrival just before the unloading of animals, blood samples were collected from each camel by venipuncture from the left jugular vein. These samples were taken directly in 2 test tubes: one ethylene diamine tetra acetic acid-dipotassium (EDTA-K2) Vacutainer tube and one heparanized tube. EDTA blood was used for Ht, NLR and hemolysis measure, wheras heparin blood was used for the determination of plasma levels of all biochemical and hormonal parameters. The plasma was separated by centrifugation at $750 \times \mathrm{g}$ for $15 \mathrm{~min}$ at $4^{\circ} \mathrm{C}$, pipetted into aliquots and then stored at $-20^{\circ} \mathrm{C}$ until analysis.

\section{Hematocrit measure}

The Hct was determined on whole blood with capillary tubes and centrifuged (hettich Haematokrit D-7200) using a microhematocrit reading device, and was expressed as follows:

$\mathrm{Ht}=$ (level of pellet/overall height)x100.

\section{Neutrophil/lymphocyte ratio determination}

To determine the leukocytes differential distribution (\%), blood smears were stained with May-Grunwald-Giemsa, i.e., 5 min of May-Grunwald and 5 min of Giemsa tenth diluted in water. On 100 leukocytes, the percentage of neutrophils (neutrophils, eosinophils, basophils), lymphocytes and monocytes, and the neutrophile to lymphocyte ratio (NLR) were determined.

\section{Hemolysis test}

Percent hemolysis $(\mathrm{H} \%)$ was determined by plotting the percent hemolysis with the concentration of salt solutions (Almizraq et al., 2013; El khasmi et al., 2015).

\section{Biochimical parameters analysis}

Plasma Glu, TP, urea, creatinine, ASAT, ALAT, CT, TG, $\mathrm{Ca}, \mathrm{Pi}$ and $\mathrm{Mg}$ concentrations were measured using a spectrophotometric (JENWAY 6320D Spectrophotometer, Model 6320D) procedure from commercially available kits (CHRONOLAB, Switzerland) according to the manufacture procedures.

\section{Hormonal parameters analysis}

Plasma COR, $\mathrm{T}_{3}$ and $\mathrm{T}_{4}$ levels were analyzed by radioimmunoassay (RIA) method in the National Center of Science and Nuclear Technical Energy in Maâmoura, Morocco, by using commercially available coated RIA tubes. The hormones were quantified according to the manufacturer's instructions. These kits using 125I radiolabelled COR, T3 or T4 proved efficient in previous experiments in dromedary camels (El Khasmi et al., 2010; 2013; 2015), and was purchased from DIAsource 
(Immunoassays S.A., Nivelles, Belgium). The areas of validation for cortisol assays included limits of detection, and precision in the standard curve following sample dilution, inter- and intra-assay coefficients of variation results were considred.

\section{Statistical analysis}

The data were expressed in SI units as mean and standard error (SE), and were analyzed by the Freidman test for comparison between the values determined in different groups and at different stages. $\mathrm{P}<0.05$ was seen as statistically significant.

\section{RESULTS AND DISCUSSION}

The impact of stress induced by transport and increasing the loading density on some physiological, hematological, biochemical and endocrine parameters in the dromedary camel has been studied in the present study. In animals transported with low (Group I) or high (Group II) density, RT, HR, RR, NLR, H50 (Table 1), and circulating levels of Glu, COR, T3 and T4 (Table 2) measured after transport, were significantly $(\mathrm{P}<0.05)$ higher than those measured before loading and transport. However, Hct (Table 1) and plasma levels of TP, urea, creatinine, ASAT, ALAT (Table 3), CT, TG, Ca, Pi and Mg (Table 4) showed no significant variations. At the end of transport before unloading, RT, HR, RR, NLR and H50 (Table 1), Glu, COR, T3 and T4 (Table 2) in camels that were transported with low density (Group I) were significantly lower $(\mathrm{P}<0.05)$ by comparison to camels that $\mathrm{n}$ were transported with high density (Group II). Wheras, in both groups, Hct (Table 1) and plasma levels of TP, urea, creatinine, ASAT, ALAT (Table 3), CT, TG, Ca, Pi and Mg (Table 4) were not influenced by the loading density.Stress is a nonspecific phenomenon that implicates several behavioural, physiological and emotional reactions in response to a variety of environmental stimuli (Vosláŕová et al., 2010). Pre-slaughter stress can start with the preparation of the animal in the farm, breeding site and market, continues with loading, transport, unloading, reception, conduction to the storage area in the slaughterhouse, and ends at the bleeding (Terlouw et al., 2005; Melesse et al., 2011; Chen et al., 2013; Miranda-de la Lama, 2013). In order to avoid stress at each of these stages, the International Committee of the World Organization for Animal Health has

Table 1: Impact of loading density on rectal temperature (RT), heart rate (HR), respiratory rate (RR), hematocrit (Hct), neutrophile/ lymphocyte ratio (NLR) and concentration of saline solution where $50 \%$ hemolysis occurs (H50) during road transport in the dromedary camel (Mean $\pm \mathrm{SE}$, ${ }^{\mathrm{a}} \mathrm{P}<0.05$ comparison before and after transport of the same group, ${ }^{\mathrm{b}} \mathrm{P}<0.05$ comparison between Groups I and II after transport)

\begin{tabular}{lcccccc} 
& $\mathbf{R T}\left({ }^{\circ} \mathbf{C}\right)$ & HR (beats/mn) & RR (cycles/min) & Hct (\%) & NLR & H50 (mosm/L) \\
\hline Group I & & & & & & \\
$\quad$ Before transport & $37.8 \pm 0.3$ & $46 \pm 3$ & $11 \pm 1$ & $33.4 \pm 2$ & $0.91 \pm 0.11$ & $123.05 \pm 3.99$ \\
After transport & $38.1 \pm 0.3$ & $53^{\mathrm{a}} \pm 3$ & $15^{\mathrm{a}} \pm 2$ & $34.61 \pm 2.83$ & $0.92 \pm 0.11$ & $132.65^{\mathrm{a}} \pm 3.99$ \\
Group II & & & & & \\
Before transport & $37.7 \pm 0.4$ & $47 \pm 4$ & $12 \pm 1$ & $33.59 \pm 2.18$ & $0.91 \pm 0.01$ & $125.16 \pm 2.22$ \\
After transport & $40.2^{\mathrm{a}, \mathrm{b}} \pm 0.4$ & $62^{\mathrm{a}, \mathrm{b} \pm 4}$ & $20^{\mathrm{a}, \mathrm{b}} \pm 2$ & $35.15 \pm 3.32$ & $1.31^{\mathrm{a}, \mathrm{b}} \pm 0.11$ & $147.65^{\mathrm{a}, \mathrm{b}} \pm 3.99$ \\
\hline
\end{tabular}

Table 2: Impact of loading density on circulating levels of glucose (Glu), cortisol (COR), triiodothyronine $\left(T_{3}\right)$ and thyroxine $\left(T_{4}\right)$ during road transport in the dromedary camel (Mean $\pm \mathrm{SE}$, aP<0.05 comparison before and after transport of the same group, ${ }^{\mathrm{b}} \mathrm{P}<0.05$ comparison between Groups I and II after transport)

\begin{tabular}{|c|c|c|c|c|}
\hline & Glu (mmoles/L) & COR (ng/mL) & $\mathrm{T}_{3}$ (nmoles/L) & $\mathrm{T}_{4}$ (nmoles/L) \\
\hline \multicolumn{5}{|l|}{ Group I } \\
\hline Before transport & $6.47 \pm 0.03$ & $28.58 \pm 0.52$ & $1.214 \pm 0.29$ & $63.62 \pm 4.01$ \\
\hline After transport & $6.90 \pm 0.04^{a}$ & $35.021 \pm 1.74^{a}$ & $1.716 \pm 0.51$ & $81.445 \pm 7.24^{\mathrm{a}}$ \\
\hline \multicolumn{5}{|l|}{ Group II } \\
\hline Before transport & $6.50 \pm 0.03$ & $25.21 \pm 0.67$ & $1.426 \pm 0.174$ & $66.50 \pm 5.86$ \\
\hline After transport & $7.20 \pm 0.02^{a, b}$ & $53.33 \pm 5.33^{a, b}$ & $3.569 \pm 1.25^{a, b}$ & $110.8 \pm 19.93^{a, b}$ \\
\hline
\end{tabular}

Table 3: Impact of loading density on plasma levels of total protein (TP), urea, creatinine and transaminases (ASAT, ALAT) during road transport in the dromedary camel (Mean \pm SE)

\begin{tabular}{|c|c|c|c|c|c|}
\hline & TP (g/dl) & Urea (mmoles/L) & Creatinine ( $\mu$ moles/L) & ASAT ( U/L ) & ALAT (U/L) \\
\hline \multicolumn{6}{|l|}{ Group I } \\
\hline Before transport & $6.25 \pm 0.16$ & $29.62 \pm 1.8$ & $0.73 \pm 0.03$ & $2.74 \pm 0.12$ & $13.15 \pm 0.47$ \\
\hline After transport & $6.21 \pm 0.10$ & $32.23 \pm 2.5$ & $0.75 \pm 0.023$ & $4.22 \pm 0.14$ & $16.23 \pm 0.51$ \\
\hline \multicolumn{6}{|l|}{ Group II } \\
\hline Before transport & $6.27 \pm 0.30$ & $29.60 \pm 0.63$ & $0.74 \pm 0.01$ & $2.81 \pm 0.08$ & $13.51 \pm 0.75$ \\
\hline After transport & $6.28 \pm 0.14$ & $32.54 \pm 2.6$ & $0.75 \pm 0.02$ & $4.33 \pm 0.16$ & $16.42 \pm 0.6$ \\
\hline
\end{tabular}




\begin{tabular}{|c|c|c|c|c|c|}
\hline & CT & TG & $\mathrm{Ca}$ & $\mathrm{Pi}$ & $\mathrm{Mg}$ \\
\hline \multicolumn{6}{|l|}{ Group I } \\
\hline Before transport & $0.92 \pm 0.01$ & $0.42 \pm 0.03$ & $2.3 \pm 0.2$ & $2.2 \pm 0.2$ & $1.3 \pm 0.3$ \\
\hline After transport & $0.95 \pm 0.07$ & $0.43 \pm 0.02$ & $2.4 \pm 0.2$ & $2.3 \pm 0.4$ & $1.2 \pm 0.3$ \\
\hline \multicolumn{6}{|l|}{ Group II } \\
\hline Before transport & $0.93 \pm 0.03$ & $0.41 \pm 0.013$ & $2.35 \pm 0.18$ & $2.25 \pm 0.092$ & $1.35 \pm 0.23$ \\
\hline After transport & $0.98 \pm 0.02$ & $0.44 \pm 0.03$ & $2.6 \pm 0.3$ & $2.4 \pm 0.5$ & $0.7 \pm 0.2$ \\
\hline
\end{tabular}

developed recommendations for each of the pre-slaughter and slaughter processes for domestic animals (Shimshony and Chaudry, 2005), without any specific one in the camel. All values of stress parameters analyzed here in the camel increased after loading and road transportation. As a very stressful factor, road transport to the slaughterhouse had been able to induce in the camel, hypercortisoleamia (Saeb et al., 2010; El Khasmi et al., 2013) and an activation of free radical generation (Nazifi et al., 2009). In this species, we had previously reported that $\mathrm{H} \%$ and circulating COR, thyroid hormones and Glu levels measured after transport were significantly higher than those observed in samples collected before transport and were positivly correlated with travel distance (El Khasmi et al., 2010; 2015). In addition to the physical effort required during transport, loading involves manipulations of camels and their exposure to new environments. These steps induce an increase in heart rate as it had been observed in calves (Lensink et al., 2001, Van de Water et al., 2003) and sheep (Baldock and Sibly, 1990), coupled with an increase in the levels of cortisol and creatine kinase in pigs (Kim et al., 2004, Brown et al., 2005). In bovine species, exposure to transport stress induced a significant increase of HR, NLR, and circulating levels of COR, Glu, lactate and heat shock protein 70 (Grigor et al., 2004; Chacon et al., 2005; Mounier et al., 2006; Chulayo et al., 2016). Furthermore, Jama et al. (2016) had found that in pigs, levels of saliva and urine cortisol and serum creatine kinase activity before transportation were lower than those analyzed at arrival at the abattoir.

During loading and road transportation, truck vibration, movement, acceleration and noise expose animals to stress, which compromises their physiological and biochemical processes then their well-being (Bourguet et al., 2011; Chulayo et al., 2012; Miranda-de la Lama et al., 2014). Under these conditions, animals showed an increase of COR and catecholamines secretion (Sporer et al., 2008; Muchenje et al., 2009; Rosado et al., 2010; Chulayo et al., 2012; 2013) resulting in increase of plasma levels of heat shock protein 70 and glucose, which were positively correlated with preslaughter distance travelled (Chulayo et al., 2016).

The impact of road ransport had been the most studied parameter in the camel (El khasmi et al., 2010; 2013;
2015) since it is the source of a large number of stressors, sometimes with extreme consequences. It had been accepted that several factors associated with transportation including physical discomfort, social character, handling, novelty of environment, adverse weather conditions, thirst, tiredness and finally deprivation of water and food, accentuate the preslaughter stress responsiveness as shown in animals (Brown et al., 1999; Karaca et al., 2016; Knowles and Warriss, 2000; Tarrant and Grandin 2000; Muchenje et al., 2009; Bourguet et al., 2011; Njisane and Muchenje, 20013) resulting in important economic losses. For example, in lambs, pre-slaughter stress induced by fasting for $24 \mathrm{~h}$ or more, reduced the meat quality in lambs (Karaca et al., 2016) and induced liveweight losses estimated at $8 \%$ in cattle and sheep (Knowles and Warriss, 2000, Tarrant and Grandin, 2000). In addition, isolation of animals from their congeners constitutes additional sources of prelaughter stress (Deiss et al., 2006, Terlouw et al., 2008).

Many research works are increasingly interested in the welfare of domestic animals and in particular the stress induced by the transport, whose impact on their physiology and the quality of their meat is very pronounced (Chacon et al., 2005; Mounier et al., 2006). We found that among physical stressors, an increase of loading density during road transportation was a potential source of preslaughter stress in the camel. In cattle, for example, levels of cortisol and creatine kinase, as well as the number of bruises observed on carcasses, increase with loading density (Tarrant et al., 1992; Terlouw et al., 2005). However, in cattle, high stocking densities may allow animal to lean against one another, which requires high effort to maintain standing and not fall (Tarrant, 1990; Knowles, 1999). In addition, in the sheep, a high loading density in the truck decreases the risk of bruising (Jarvis and Cockram, 1994). Compared to other domestic animals, the loading and transport of camels is difficult for the operator and difficult for the animal because of its large size and its aggressiveness when it is stressed. In our investigation, the camels were transported in a squatting position holding the forelegs tight by a rope at the knees. They require experience in all stages of preslaughter processes including the loading and road transport (Kadim et al., 2013). 


\section{CONCLUSION}

In the dromedary camel, the loading and stocking density may be considered as preslaughter stressfull factors capable of altering physiological, hematological, biochemical and hormonal profiles and the welfare of the animal, and would be able to influence the postmortem quality of its meat. Preslaughter stress responses observeed here in the camel, are a shared responsibility between different actors. The impact of this factor on the antioxidant status of this species will be studied later.

\section{ACKNOWLEDGMENTS}

The authors thank the President of urban municipalities of Casablanca and Dr. ABOUHAFS Rachid the responsible for prefectural veterinary service of Casablanca, to carry out this work.

\section{REFERENCES}

Almizraq, R., J. D. Tchir, J. L. Holovati and J. P. Acker. 2013. Storage of red blood cells affects membrane composition, microvesiculation, and in vitro quality. Transfusion. 53: 2258-2267.

Baldock, N. M. and R. M. Sibly. 1990. Effects of handling and transportation on the heart rate and behaviour of sheep. Appl. Anim. Behav. Sci. 28: 15-39.

Bourguet, C., V. Deiss, C. Cohen-Tannugi and E. M. C. Terlouw. 2011. Behavioural and physiological reactions of cattle in a commercial abattoir: Relationships with context and animal characteristics. Meat Sci. 88: 158-168.

Bourguet, C., V. Deiss, M. Gobert, D. Durand, A. Boissy and E. M. C. Terlouw. 2010. Characterising the emotional reactivity of cows to understand and predict their stress reactions to the slaughter procedure. Appl. Anim. Behav. Sci. 125: 9-21.

Broom, D. M. 2014. Welfare of transported animals: Factors influencing welfare and welfare assessment. In: T. Grandin (Ed.), Livestock Handling and Transport. 4th ed. CABI, Wallingford, Oxfordshire, pp. 23-38.

Brown, S. N., T. G. Knowles, J. E. Edwards and P. D. Warriss. 1999. Relationship between food deprivation before transport and aggression in pig held in lairage before slaughter. Vet. Record. 145: 630-634.

Brown, S. N., T. G. Knowles, L. J. Wilkins, S. A. Chadd and P. D. Warriss. 2005. The response of pigs to being loaded or unloaded onto commercial animal transporters using three systems. Vet. J. 170: 91-100.

Chacon, G., S. Garcia-Belenguer, M. Villarroel and G. A. Maria. 2005. Effect of transport stress on physiological responses of male bovines. Dtsch Tierarztl Wochenschr. 112: 465-469.

Chen, X. Y., R. S. Jiang and Z. Y. Geng. 2013. Differential effects of two indigenous broilers exposed to cold stress and characters of follicle density and diameter. Ital. J. Anim. Sci. 10: 38-41.

Chulayo, A. Y., G. Bradley and V. Muchenje. 2016. Effects of transport distance, lairage time and stunning efficiency on cortisol, glucose, HSPA1A and how they relate with meat quality in cattle. Meat Sci. 117: 89-96.

Chulayo, A. Y. and V. Muchenje. 2013. The effects of pre-slaughter stress and season on the activity of plasma creatine kinase and mutton quality from different sheep breeds slaughtered at a smallholder abattoir. Asian Aust. J. Anim. Sci. 26: 1762-1772.

Chulayo, A. Y., O. Tada and V. Muchenje. 2012. Research on preslaughter stress and meat quality: A review of challenges faced under practical conditions. Appl. Anim. Husb. Rural Develop. 5: 1-6.

Dalla Costa, O.A., L. Faucitano, A. Coldebella, J. V. Ludke, J. V. Peloso, D. Dalla Roza and M. J. R. Paranhos da Costa. 2007. Effects of the season of the year, truck type and location on truck on skin bruises and meat quality in pigs. Livest. Sci. 107: 29-36.

De la Fuente, J., M. Sanchez, C. Perez, S. Lauzurica, C. Vieira, E. Gonzalez de Chavarri and M. T. Diaz. 2010. Physiological response and carcass and meat quality of suckling lambs in relation to transport time and stocking density during transport by road. Animal. 4: 250-258.

Deiss, V., T. Astruc, C. Ferreira and E. M. C. Terlouw. 2006. Anesthésie gazeuse des porcs: Réponses physiologiques et comportementales à différents mélanges gazeux. Viandes and Produits Carnés. 25: 71-82.

Deiss, V., D. Temple, S. Ligout, C. Racine, J. Bouix, C. Terlouw and A. Boissy. 2009. Can emotional reactivity predict stress responses at slaughter in sheep? Appl. Anim. Behav. 119: 193-202.

El Khasmi, M., Y. Chakir, R. Bargaâ, K. Barka, I. Lektib, N. El Abbadi, A. Belhouari and B. Faye. 2015. Impact of transport distance on stress biomarkers levels in dromedary camel (Camelus dromedarius). Emirates J. Food Agric. 27: 507-512.

El Khasmi, M., Y. Chakir, F. Riad, A. Safwate, E.Tahri, M. Farh, N. El Abbadi, R. Abouhafs and B. Faye. 2013. Effects of transportation stress during the hot-dry season on some haematological and physiological parameters in moroccan dromedary camels (Camelus dromedarius). J. Life Sci. (USA). 7: $13-25$.

El Khasmi, M., F. Riad, A. Safwate, E. Tahri, M. Farh, N. El Abbadi, V. Coxam and B. Faye. 2010. Effects of preslaughter stress on meat quality and phosphocalcic metabolism in camels (Camelus dromedarius). J. Camelid Sci. 3: 33-38.

Fraukner, W. R. and J. W. King. 1970. Manual of Clinical Laboratory Procedures. Clevel, Ohio, p. 354.

Grandin, T. 2013. Making slaughterhouses more humane for cattle, pigs and sheep. Ann. Rev. Anim. Biosci. 1: 491-512.

Grigor, P. N., M. S. Cockram, W. B. Steele, J. Mclntyre, C. L. Williams, I. E. Leushuis and C. G. van Reenen. 2004. A comparison of the welfare and meat quality of veal calves slaughtered on the farm with those subjected to transportation and lairage. Livest. Produc. Sci. 91: 219-228.

Jama, N., V. Maphosa, L. C. Hoffman and V. Muchenje. 2016. Effect of sex and time to slaughter (transportation and lairage duration) on the levels of cortisol, creatine kinase and subsequent relationship with pork quality. Meat Sci. 116: 43-49.

Jarvis, A. M. and M. S. Cockram. 1994. Effects of handling and transport on bruising of sheep sent directly from farms to slaughter. Vet. Rec. 135: 523-527.

Kadim, I. T., M. M. Farouk, O. Mahgoub and A. E. Bekhit. 2013. Slaughtering and Processing of Camels. In: I. T. Kadim, (Ed),. Camel Meat and Meat Products, CAB International, pp. 54-72.

Karaca, S., S. Erdoğan, D. K. and A. Kor. 2016. Effects of pre-slaughter diet/management system and fasting period on physiological indicators and meat qualitytraits of lambs. Meat Sci. 116: 67-77.

Kim, D. H., J. H. Woo and C. Y. Lee. 2004. Effects of stocking density and transportation time of market pigs on their behaviour, plasma concentrations of glucose and stress-associated enzymes and carcass quality. Asian-Aust. J. Anim. Sci. 17: 116-121. 
Knowles, T. G. 1999. A review of the road transport of cattle. Vet. Rec. 144: 197-201.

Knowles, T. G. and P. D. Warriss. 2000. Stress physiology of animals during transport. In: Grandin, T., (Ed), Livestock Handling and Transport. $2^{\text {nd }}$ ed. CABI Publishing, Wallingford, UK.

Lensink, B. J., X. Fernandez, G. Cozzi, L. Florand and I. Veissier. 2001. The influence of farmers' behavior on calves' reactions to transport and quality of veal meat. J. Anim. Sci. 79: 642-652.

Melesse, A., S. Maak, R. Schmidt and G. Von Lengerken. 2011. Effect of long-term heat stress on enzyme activities and T3 levels in commercial layer hens. Int. J. Livest. Prod. 2: 107-116.

Miranda-de la Lama, G. C. 2013. Transport and pre-slaughter logistics: Definitions and current tendencies in animal welfare and meat quality. Vet. Mexico. 44: 31-56.

Miranda-de la Lama, G. C., M. Villarroel and G. A. María. 2014. Livestock transport from the perspective of the pre-slaughter logistic Chain: A review. Meat Sci. 98: 9-20.

Mounier, L., H. Dubroeucq, S. Andanson and I. Veissier. 2006. Variations in meat $\mathrm{pH}$ of beef bulls in relation to conditions of transfer to slaughter and previous history of the animals. J. Anim. Sci. 84: 1567-1576.

Muchenje, V., K. Dzama, M. Chimonyo, P. E. Strydom and J. G. Raats. 2009. Relationship between pre-slaughter stress responsiveness and beef quality in three cattle breeds. Meat Sci. 81: 653-657.

Nazifi, S., S. Mahdi, B. Hasan and S. Saeedeh. 2009. Influence of road transportation during hot summer conditions on oxidative status biomarkers in Iranian dromedary camels (Camelus dromedarius). Afr. J. Biochem. Res. 3: 282-287.

Nielsen, B. L., L. Dybkjaer and M. S. Herskin. 2011. Road transport of farm animals: Effects of journey duration on animal welfare. Animal. 5: 415-427.

Njisane, Y. Z. and V. Muchenje. 20013. Influence of municipal abattoir conditions and animal-related factors on avoidance behaviour, bleeding times at slaughter and the quality of lamb meat. Asian Aust.. J. Anim. Sci. 26: 1496-1503.

Rosado, B., S. García-Belenguer, M. León, G. Chacón, A. Villegas and J. Palacio. 2010. Blood concentrations of serotonin, cortisol and dehydroepiandrosterone in aggressive dogs. Appl. Anim.
Behav. Sci. 132: 124-130.

Rostagno, M. H. 2009. Can stress in farm animals increase food safety risk? Food Borne Pathog. Dis. 6: 767-776.

Saeb, M., H. Baghshani, S. Nazifi and S. Saeb. 2010. Physiological response of dromedary camels to road transportation in relation to circulating levels of cortisol, thyroid hormones and some serum biochemical parameters. Trop. Anim. Health Prod. 42: 55-63.

Shimshony, A. and M. M. Chaudry. 2005. Slaughter of animals for human consumption. Rev. Sci. Tech. 24: 693-710.

Sporer, K. R. B., P. S. D. Weber, J. L. Burton, B. Earley and M. A. Crowe. 2008. Transportation of young beef bulls alters circulating physiological parameters that may be effective biomarkers of stress. J. Anim. Sci. 86: 1325-1334.

Tarrant, P. V. and T. Grandin. 2000. Cattle transport. In: Grandin, T. (Ed.), Livestock handling and transport ( $2^{\text {nd }}$ ed), CABI Publishing, Wallingford, UK, pp. 151-173.

Tarrant, P. V., F. J. Kenny, D. Harrington and M. Murphy. 1992. Long distance transportation of steers to slaughter: Effect of stocking density on physiology, behaviour and carcass quality. Livest. Prod. Sci. 30: 223-238.

Tarrant, P.V. 1990. Transportation of cattle by road. Appl. Anim. Behav. Sci. 28: 153-170.

Terlouw, E. M. C. and P. Rybarczyk. 2008. Explaining and predicting differences in meat quality through stress reactions at slaughter: The case of large white and Duroc pigs. Meat Sci. 79: 795-805.

Terlouw, E. M. C., J. Porcher and X. Fernandez. 2005. Repeated handling of pigs during rearing. II. Effect of reactivity to humans on aggression during mixing and on meat quality. J. Anim. Sci. 83: 1664-1672.

Van de Water, G., F. Verjans and R. Geers. 2003. The effect of short distance transport under commercial conditions on the physiology of slaughter calves; $\mathrm{pH}$ and colour profiles of veal. Livest. Prod. Sci. 82: 171-179.

Voslářová, E., P. Chloupek, S. Steinhauser, J. Havlíček and V. Večerek. 2010. Influence of housing system and number of transported animals on transport-induced mortality in slaughter pigs. Acta Vet. Brno. 79: S79-S84. 